\title{
Bed composition generation for morphodynamic modeling: case study of San Pablo Bay in California, USA
}

\author{
Mick van der Wegen - Ali Dastgheib • Bruce E. Jaffe • \\ Dano Roelvink
}

Received: 25 November 2009 / Accepted: 29 June 2010 / Published online: 15 July 2010

(C) The Author(s) 2010. This article is published with open access at Springerlink.com

\begin{abstract}
Applications of process-based morphodynamic models are often constrained by limited availability of data on bed composition, which may have a considerable impact on the modeled morphodynamic development. One may even distinguish a period of "morphodynamic spin-up" in which the model generates the bed level according to some ill-defined initial bed composition rather than describing the realistic behavior of the system. The present paper proposes a methodology to generate bed composition of multiple sand and/or mud fractions that can act as the initial condition for the process-based numerical model Delft3D. The bed composition generation (BCG) run does not include bed level changes, but does permit the redistribution of multiple sediment fractions over the modeled
\end{abstract}

Responsible Editor: Ashish Mehta

M. van der Wegen $(\bowtie) \cdot$ A. Dastgheib $\cdot$ D. Roelvink

UNESCO-IHE,

PO Box 3015, 2601 DA Delft, the Netherlands

e-mail: m.vanderwegen@unesco-ihe.org

A. Dastgheib

e-mail: a.dastgheib@unesco-ihe.org

D. Roelvink

e-mail: d.roelvink@unesco-ihe.org

B. E. Jaffe

USGS Pacific Science Center,

400 Natural Bridges Drive,

Santa Cruz, CA 95060, USA

e-mail: bjaffe@usgs.gov

D. Roelvink

Delft University of Technology,

PO Box 5048, 2600 GA Delft, the Netherlands

D. Roelvink

Deltares,

PO Box 177, $2600 \mathrm{MH}$ Delft, the Netherlands domain. The model applies the concept of an active layer that may differ in sediment composition above an underlayer with fixed composition. In the case of a BCG run, the bed level is kept constant, whereas the bed composition can change. The approach is applied to San Pablo Bay in California, USA. Model results show that the BCG run reallocates sand and mud fractions over the model domain. Initially, a major sediment reallocation takes place, but development rates decrease in the longer term. Runs that take the outcome of a BCG run as a starting point lead to more gradual morphodynamic development. Sensitivity analysis shows the impact of variations in the morphological factor, the active layer thickness, and wind waves. An important but difficult to characterize criterion for a successful application of a BCG run is that it should not lead to a bed composition that fixes the bed so that it dominates the "natural" morphodynamic development of the system. Future research will focus on a decadal morphodynamic hindcast and comparison with measured bathymetries in San Pablo Bay so that the proposed methodology can be tested and optimized.

Keywords Process-based model · Morphodynamic prediction - Bed composition - Estuarine processes .

San Pablo Bay · Data scarcity · Coastal geomorphology

\section{Introduction}

Morphodynamic evolution describes bathymetric development over time. In recent decades, considerable effort has been undertaken to understand, hindcast, and predict morphodynamic developments in the tidal environment. This is relevant since changes in the location of channels and shoals have an impact on navigation. Also, estuarine 
ecology may be affected, for example by degradation of the intertidal areas that act as feeding grounds for birds and other (aquatic) fauna. Ecological and economical values and functions in the estuarine environment are thus closely linked to morphodynamic development.

Modeling of morphodynamic development in estuaries is relevant to understanding and assessing the natural behavior of the morphological system, such as the development toward an assumed equilibrium condition (Lanzoni and Seminara 2002; Todeschini et al. 2008; Van der Wegen and Roelvink 2008; Van der Wegen et al. 2008), as well as the consequences of anthropogenic influences, such as the impact of breakwater construction and access channel dredging (Yongjun et al. 2009; Zanuttigh 2007; Lesser et al. 2004) or changing sediment supply toward the estuary by dam construction (Ganju et al. 2009). Over longer timescales, climate changes are an increasingly relevant issue. Examples of processes are sea level rise, changing river regimes, and changing sediment loads (Ganju and Schoellhamer 2010).

Different approaches for long-term morphological modeling have been described in literature. De Vriend et al. (1993) distinguish two types of approaches to long-term mathematical morphological modeling developed more or less sequentially. Behavior-oriented (or aggregated) modeling focuses on empirical relations between different types of coastal parameters without describing the underlying physical processes. In contrast, process-based modeling is based on a detailed description of the underlying physical processes. Application of a process-based model always implies that reality is reduced in such a way that no relevant processes are lost, but that, at the same time, not too many processes are included that would increase computational time too much. Furthermore, Seminara and Blondeaux (2001) distinguish between the reductionist and the holistic approach. The reductionist approach is based on strongly idealized input and output parameters. It originates from the idea that "...understanding the behavior of complex systems requires that the fundamental mechanisms controlling the dynamics of its parts must be firstly at least qualitatively understood" (Seminara and Blondeaux 2001). The holistic approach involves detailed descriptions of the physical processes and "... assumes that the complete nature of the system can be investigated by tools that describe its overall behavior..." (Seminara and Blondeaux 2001). Following these definitions, the present research applies a process-based, holistic modeling approach.

Process-based models can represent morphodynamic developments in domains of hundreds of square meters up to several tens of square kilometers over time spans of months up to millennia (Van der Wegen and Roelvink 2008; Van der Wegen et al. 2008). These models are driven by the hydrodynamic boundary conditions and calculate non-stationary water level gradients and resulting velocities over the model domain. By application of a sediment transport formula, sediment load can be calculated based on the velocity field. Finally, bathymetric development is predicted from the divergence of the sediment load, and the updated bed level is used in the next time step of hydrodynamic calculations. This process repeats in time so that it includes nonlinear feedbacks between hydrodynamics and the morphological features. Thus, morphodynamic hindcasting and predictions can be made.

Researchers that apply morphodynamic models are often confronted with limited availability of bathymetric data for calibration and validation. On the one hand, data such as water levels, discharges, and velocities are relatively easily available, although not at every location and only for limited periods in time. However, morphological data such as bathymetry are more difficult to obtain because they require long-term and costly measurement campaigns. Because of relatively slow developments in nature, estuarine bathymetric changes are measured sometimes only over decadal intervals (Jaffe et al. 2007).

Data on bed composition and sediment properties are usually even more poorly documented. These data are, however, required for adequate morphodynamic predictions, especially considering systems with diverse sediment characteristics such as mud, silt, and sand. In these systems, modeling efforts with single-sized sediment do not lead to correct results. On the other hand, when multiple, graded sediment fractions are used in the model, there will be the need for a careful specification of their characteristics as well as their initial distributions over the model domain.

\subsection{Objective of the study}

The aim of the research summarized in this paper was to investigate the possibilities of generating bed composition for a known bathymetry that can act as the initial condition for morphodynamic models. For the generation of bed composition, use was made of the $3 \mathrm{D}$, process-based numerical model, Delft 3D. The developed methodology is applied to San Pablo Bay in California, USA.

The essential idea is that, given a set of sediment fractions, a special bed composition generation (BCG) run can generate a distribution of sediments over the model domain that is commensurate with the prevailing hydrodynamic conditions corresponding to the initial bathymetry. For example, starting from a bathymetry with uniformly distributed fine and coarse sediments, the BCG run transports fines from channels to shoals, i.e., from areas with prevailing high shear stresses to areas with low shear stresses. At the same time, coarse sediments able to withstand high stresses are left behind in the channels. The bed composition thus obtained can act as the basis for further prediction of morphodynamic development. 
The following sections describe the area of interest (San Pablo Bay), model definition and setup (including the bed composition model), and model results.

\subsection{Area of interest}

San Pablo Bay (covering an area of about $225 \mathrm{~km}^{2}$ ) is part of the northern reach of the San Francisco Estuary (Fig. 1). The Sacramento River and the San Joaquin River confluence in an area referred to as the Delta and discharge into the Pacific subsequently via Suisun Bay, San Pablo Bay, and the Central (San Francisco) Bay. Apart from a sandy, 20-m-deep main channel transecting San Pablo Bay from east to west, large parts are shallow ( $<5 \mathrm{~m}$ deep) and muddy (Fig. 2). High river discharges occur during winter or spring amounting to as much as $15,000 \mathrm{~m}^{3} / \mathrm{s}$, although the discharge strongly varies over years. The duration of high discharges can be several days up to weeks, and several high discharge peaks may occur during one wet season. The majority of sediment is supplied to San Pablo Bay during these high discharge events. During the remainder of the year, discharges are low, in the range of $200-600 \mathrm{~m}^{3} / \mathrm{s}$. Further details on the hydrological system may be found in Kimmerer (2004) and references therein.

Hydraulic mining for gold in the foothills of the Sierra Nevada range from 1852 to 1884 caused an excessive supply of sediments from the rivers toward the bay area. It is believed that large volumes of this sediment settled in the Delta, Suisun Bay, and San Pablo Bay during that period and some time afterwards due to lag effects. Since hydraulic mining ended and reservoir construction upstream of the Delta trapped sediment, Suisun Bay started to erode beginning the twentieth century, whereas San Pablo Bay became erosional mid-twentieth century. Comparison of historical bathymetries in 1856, 1887, 1898, 1920, 1951, and 1983

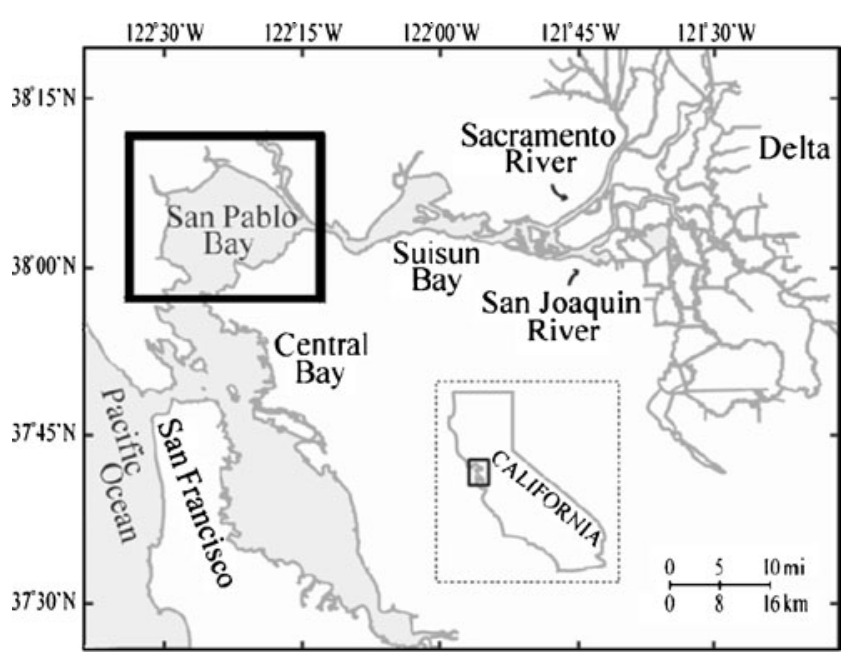

Fig. 1 Location of San Pablo Bay in California, USA confirm these developments (Cappiella et al. 1999; Jaffe et al. 2007).

Currently, research effort is underway to predict future morphodynamic developments in San Pablo Bay and Suisun Bay (Ganju and Schoellhamer 2010). A central question in this research relating to bathymetric developments could be expected under different climate change scenarios. Numerical, 3D, process-based models (ROMS and Delft3D) are being used as tools. In order to validate these models, hindcasts of the depositional period (1856-1887; Ganju et al. 2009; Van der Wegen et al., submitted) and the erosional period (1953-1983; Ganju and Schoellhamer 2010) have been made.

\subsection{Sediment characteristics}

Apart from the limited historical hydrodynamic and bathymetric data, limited data on bed composition and sediment supply are available for the 1856-1887 period and the 19531983 period. Ganju et al. (2008) developed a methodology to estimate the yearly past sediment loads and a characteristic morphological hydrograph.

Locke (1971) reports the outcome of a field campaign for the bed sediment samples in San Pablo Bay in the winters of 1968, 1969, and 1970. He collected 63 samples and determined sediment size characteristics. Figure $2 \mathrm{~b}$ maps the distribution of the median grain size, $D_{50}$. He reports that poorly sorted silty-clay samples were dominant, that the sand fraction varied considerably, and that the relative silt and clay fractions remained more or less constant. Silt (size between 4 and $62 \mu \mathrm{m}$ ) was found in the main channel and along the edges of the bay. Clay (size smaller than $4 \mu \mathrm{m}$ ) was found on the central part of the large shoal north of the channel and the shoal southeast of the channel. Patches of sand (size larger than $62 \mu \mathrm{m}$ ) were found in the main channel. Samples from the northern shoals were poorly sorted, whereas the channel sediments and sediments from the southwestern shoal and some eastward patches in the channel were well sorted. Locke (1971) observed considerable seasonal fluctuations of the size fractions, especially in the main channel, which was more silty in spring and summer (after the high river discharge) and contained coarser material during winter months.

Jones (2008) carried out sediment and bed composition analyses of three cores taken at the channel edge northwest of the main channel in the bay (see circle in Fig. 2a). Data were obtained on the critical shear stress for erosion $\left(\tau_{\mathrm{e}-\mathrm{cr}}\right)$, the erosion rate constant $(M)$, the bulk density $\left(\rho_{\mathrm{b}}\right)$, water content, and particle size distribution. Although this analysis considers only one location in San Pablo Bay, it shows that the critical shear stress increases at larger core depths and that the bulk density and the median dispersed 
Fig. 2 a 1856 San Pablo Bay bathymetry with 5-m depth contours. Circle denotes area of core samples. b Measured sediment distribution in San Pablo Bay 1968-1970 after Locke (1971)

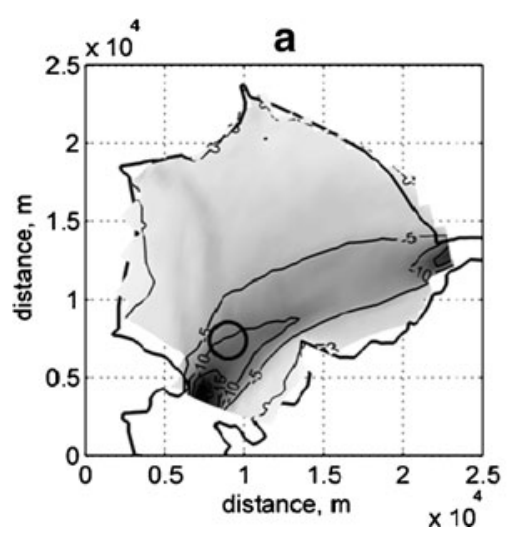

particle size $D_{50}$ remain fairly constant over the first $20 \mathrm{~cm}$ (Table 1). The material seems silty by definition, although it remains unclear how it settled. In the San Francisco Estuary, flocculation is significant (Ganju et al. 2007), so particle fall velocity cannot be determined directly from the dispersed sediment.

\section{Model description}

\subsection{General framework}

Lesser et al. (2004) and Van der Wegen and Roelvink (2008) describe the Delft3D model as applied in the present analysis. Delft 3D solves the Reynolds-averaged NavierStokes equations (including the $k-\varepsilon$ model for turbulence closure) and calculates the sediment load based on the generated flow field. The bathymetry is updated every time step based on the divergence of the sediment load field. Since in general morphodynamic development is much slower than the hydrodynamic processes, the calculated bed level change is multiplied by a specially introduced morphological factor every time step to enhance morphodynamic development (Roelvink 2006). Roelvink (2006) argues that this approach is valid as long as the bed level change per time step does not disturb the flow significantly and does not exceed $5 \%$ of the water depth. Van der Wegen and Roelvink (2008) provide a sensitivity analysis of the morphological factor. Their analysis shows that 1 month of calculations with a morphological factor of 400 leads to

Table 1 Example of sediment analysis results from Jones (2008)

\begin{tabular}{lccc}
\hline Depth below bed level $(\mathrm{m})$ & $D_{50}(\mu \mathrm{m})$ & $\rho_{\mathrm{b}}\left(\mathrm{kg} / \mathrm{m}^{3}\right)$ & $\tau_{\mathrm{e}-\mathrm{cr}}(\mathrm{Pa})$ \\
\hline 0 & 13.26 & 1,370 & 0.26 \\
0.057 & 10.11 & 1,370 & 0.91 \\
0.1 & 12.21 & 1,460 & 1.92 \\
0.16 & 10.61 & 1,350 & 1.74 \\
0.21 & 10.92 & 1,380 & 2.56 \\
\hline
\end{tabular}

similar results as 40 months of calculations with a morphological factor of 10 . Salinity-induced density differences and waves (via the SWAN model, Booij et al. 1999) are included. Different sediment transport formulations can be defined as well as multiple sand and mud fractions. The next sections describe the bed composition model and model configuration for San Pablo Bay.

\subsection{Bed layer model}

Hirano (1971) introduced the active layer concept for bed layer models in which a homogeneous active bed layer is allowed to change in composition and elevation. This layer is located on top of an underlayer fixed in position and composition. Blom (2008) describes the Hirano (1971) model and three other more advanced sediment continuity models for non-uniform sediments and compares them to laboratory flume tests. Here, we will briefly describe the Hirano (1971) model, as applied in the present study with a slight adaptation.

Similar to the grid of the hydrodynamic numerical model, the bathymetry is subdivided into cells. These bed cells can have an infinitely deep layer of sediment, but for the present work, they are assigned a sediment layer of limited thickness. A bed cell consists of different numerical layers. Located on top of the bed, the active layer has a fixed height and interacts with the water column via sediment erosion and deposition. Different layers of specified heights may be located below the active layer (so-called underlayers). These layers permit specifications of bed composition and sediment characteristics (for example a higher critical shear stress for erosion or bulk density for deeper, more consolidated layers). In a standard morphodynamic model, the active layer will rise or fall in case of net deposition or erosion during a morphodynamic run, whereas the underlayers remain at constant elevations.

For the present work, the bed level is not allowed to change. The active layer is at a constant level, and the underlayers may move up or down. Figure 3 schematically shows what happens when a bed cell erodes or gains 
Fig. 3 Schematic representation of fine sediment: erosion (a) and deposition (b) with active layer $(A L)$ and initially two underlayers $(U L)$ with initially uniform sediment distribution over different layers. Arrows indicate erosion (a) or deposition (b). Darker colors indicate coarser mean sediment diameter in specific layer

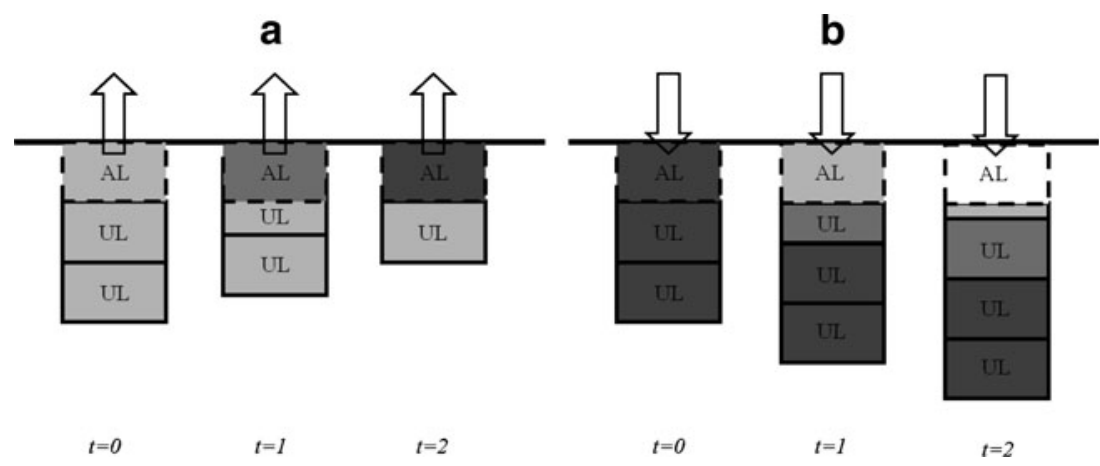

sediment due to the prevailing hydrodynamic conditions. When sediment erodes from the active layer (Fig. 3a), a similar volume of sediment is taken from the underlayer with the same composition as the underlayer. In this way, over time, the underlayers "erode." The active layer becomes coarser because the fines are eroded in subsequent time steps and coarser material is left behind. In case of deposition (Fig. 3b), the fines make the composition of the active layer finer. A new underlayer develops with composition that is finer than the other underlayers, but coarser than the active layer. The number of underlayers will increase and the underlayers will move down.

For the present study, the sediment is taken to be initially uniformly distributed over the model domain. Each bed cell consists of six sediment fractions, each fraction accounting for $16.7 \%$ of the cell volume. Per fraction, 1-m-thick sedimentary material is available so that a total of $6 \mathrm{~m}$ of sediment is available in each cell. The sediment volume may differ per fraction depending on the specified porosity of the fraction. Based on comparisons with measurements, Blom (2008) found best results for the Hirano (1971) model with an active layer thickness scaled to the dune height. In the present study, the active layer had a thickness of $0.25 \mathrm{~m}$ and the underlayer thickness was $6 \mathrm{~m}$. Preliminary model results showed that this underlayer height was sufficient to allow continuous erosion during model runs without depleting the sediment source in the cells. Also, it seems important for numerical stability that typical values of changes in the bed level or underlayer thickness per time step do not exceed the active layer thickness. The reason behind this is that the sediment content of the active layer must vary only slightly and must not be replaced within one time step. Changes in the bed level or underlayer thickness during the model runs appeared to be $4 \mathrm{~cm}$ maximum, which is only about $20 \%$ of the active layer thickness.

Each sediment fraction erodes or deposits in the bed cell according to erosion and deposition processes following from the sediment transport formulations. The volume of eroding material is proportional to sediment availability in a cell. In other words, if a cell consists of $20 \%$ of fraction " $A$ " and the calculated erosion of this fraction is $5 \mathrm{~mm}$ for the total cell surface, only $20 \%$ of $5 \mathrm{~mm}(=1 \mathrm{~mm})$ will be eroded. The model does not account for physical interactions between the fractions. For example, erosion of a sand fraction is not influenced by the presence of mud, although this may have considerable impact in reality (see, for example, Van Ledden et al. 2006).

As mentioned, in order to speed up the changing rate of bed composition, the model applies a morphological factor (Roelvink 2006). This means that every time step, the calculated bed composition change in the active layer and the underlayers is multiplied by a factor (equal to 100 in this study). Once a certain "stable" bed composition is reached, the bed composition in the upper layer (i.e., at the surface) obtained by the BCG run can be used as the initial bed condition for runs including bed level changes. The underlayer may then have the same characteristics as the upper layer. The following section addresses this "stability" criterion as well as the sensitivity of the model outcomes to variations in the model parameter settings.

\subsection{San Pablo Bay model configuration}

The model grid includes Suisun Bay east of San Pablo Bay and extends to the northern part of the Central Bay due southwest. The grid is curvilinear with a typical cell size of $150 \times 150 \mathrm{~m}$ (Fig. 4). The model consists of 15 sigma layers in the vertical direction.

\subsection{Selection of boundary conditions}

Tidal water level boundary conditions at the seaward end and discharge boundary conditions at the landward end were generated using a large hydrodynamic model covering the entire San Francisco Estuary. Calibration of this model was carried out both for a representative low-discharge period and a high-discharge period. Tidal boundary conditions were limited to the main constituents $\mathrm{M}_{2}, \mathrm{M}_{4}$, and $\mathrm{C}_{1}$ (an artificial combination of $\mathrm{O}_{1}$ and $\mathrm{K}_{1}$ ) so that tidal forcing consisted of regular near-daily cycles. The criterion for the derivation of the artificial $\mathrm{C}_{1}$ constituent was that it would lead to tidal residual sediment load equal to the load 
Fig. 4 Numerical grid covering San Pablo Bay and Suisun Bay. The upper branch at the landward (right) side represents the Sacramento River and the lower branch the San Joaquin River

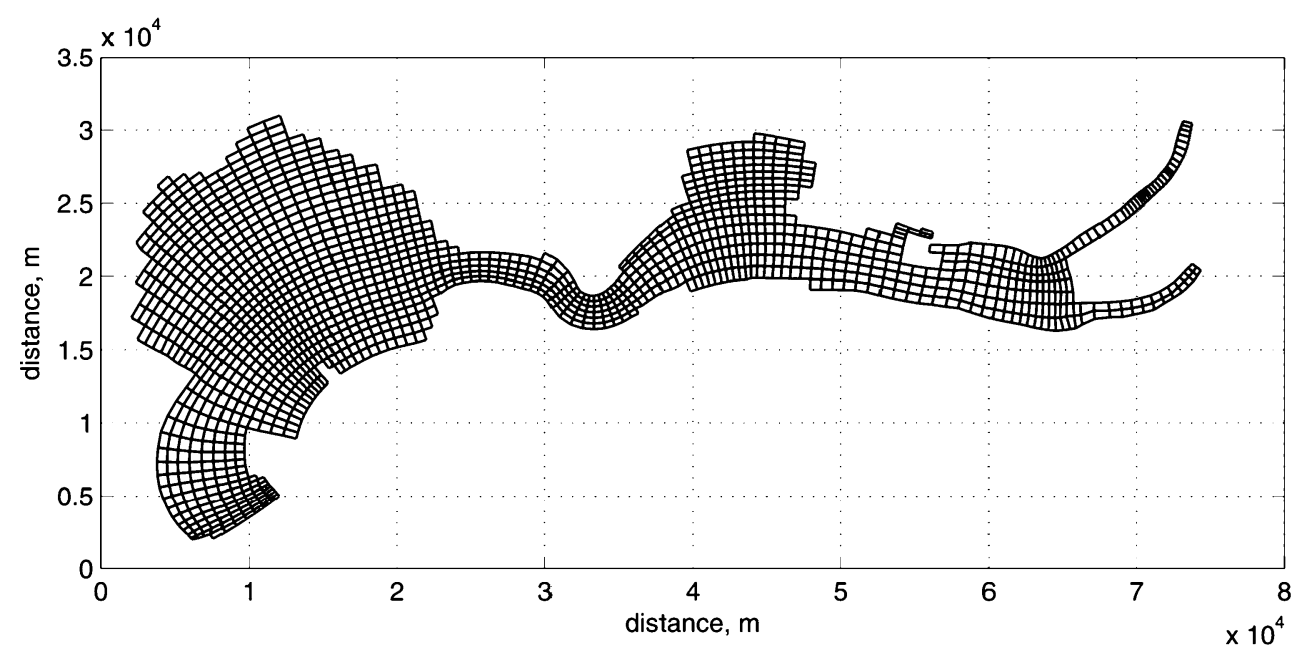

obtained by the combination of the $\mathrm{O}_{1}$ and $\mathrm{K}_{1}$ constituents (Hoitink et al. 2003; Lesser 2009).

A BCG run requires boundary conditions that are representative of the system under consideration. The San Pablo Bay system exhibits considerable seasonal fluctuations. For example, the bed composition of the bay channel is muddier in the spring and summer months after a high river flow (Locke 1971). Therefore, one should define the bay's landward boundary condition ideally in terms of a hydrograph over a representative year. This, however, only partially defines the system since river discharges during the wet season vary considerably over years.

Schematically, the hydrological characteristics in San Pablo Bay over 1 year can be subdivided into a wet season with high river discharge (about 2 months per year) and a dry season with considerably lower river discharge (about 10 months per year). It was decided to select the dry period boundary condition for the BCG runs because this condition prevails most of the time. An additional, more opportunistic motivation was that the present study is focused on the BCG methodology. An advantage of the application of the constant river discharge dry season boundary condition is that it is simple compared to the fluctuating wet season condition so that results can be interpreted in a more straightforward way.

Historical sediment concentrations at the river boundary were defined following suggestions by Ganju and Schoellhamer (2007). Sediment concentration boundary conditions were set at zero, but also allowed for a socalled Thatcher-Harleman time lag of $120 \mathrm{~min}$. This is the return time for concentration from its value in the outflow relative to its value specified in the inflow. This implies that sediment concentration entering the model domain during flood is determined during the time lag by the concentration leaving the model domain during ebb by means of a temporary storage of concentration data. The 1856 bathym- etry was applied in the present study. In order to save computational time, waves were excluded from the analysis, apart from one run for an assessment of the sensitivity of model results to the presence of waves.

\subsection{Selection of sediment fractions}

The number of sediment fractions and their characteristics depends on local conditions. Apart from selection based on (scarce) measurements, the definition of sediment fractions requires judgment or some trial and error runs. In order to limit the computation time, it is best to include as few fractions as possible, which also makes interpretation of the model results easier. On the other hand, uniform sediment does not occur in nature, so sediments are characterized by a range of classes. A further advantage of considering fractions is that it generates an insight into the behavior of different fractions in the model domain. It gives an indication of what kind of sediment can "survive" in the domain. Some fractions will be simply winnowed away (being too fine), whereas others may not move at all (being possibly too coarse). This does not mean that these fractions do not occur in the model domain, but only that they do not play a significant role in the morphodynamic development of the system.

Based on the modeling experience obtained during this study, four modeling guidelines proved valuable for selecting relevant sediment classes.

1. The BCG run should not entirely wash out the finest (mud) fractions.

2. The coarsest material (usually sand) should not be washed out during the BCG run. This would ensure that either the coarsest material is able to withstand largest shear stresses or that spatial transport gradients of the coarsest material remain small during the $\mathrm{BCG}$ run. 
3. It is suggested to take the percentage of the coarsest material to be somewhat larger than the ratio of the active layer to the sediment layer. This means that if all other sediment fractions were to erode from the sediment layer, the active layer would only consist of the coarsest fraction, which would hamper further erosion and allow the finer fractions to be redistributed before all sediment is removed from the cell (or large parts of the model domain, which would make the method unworkable).

4. The initial distribution of fractions over the domain should be in accordance with the observed distribution as far as possible.

5. Other fractions may be defined between the coarsest and the finest ones.

The above methodology implies that the domain is covered by a range of sediment from fine that is not washed out up to the material that hardly moves. It also implies that all fractions are available in the model domain or provided through the model boundaries. It is questionable whether this assumption is reasonable for every system. For example, depending on the history of a system, parts of it may not be covered by fine material since it is simply not available. Also, the assumed availability of a range of sediments and especially the coarsest material may fix the system to such an extent that subsequent model runs allowing for bed level updates do not show realistic morphodynamic development.

The present study is limited to six fractions, i.e., three sand and three mud. The sand fractions have diameters of $800 \mu \mathrm{m}\left(\mathrm{s}_{1}\right), 300 \mu \mathrm{m}\left(\mathrm{s}_{2}\right)$, and $150 \mu \mathrm{m}\left(\mathrm{s}_{3}\right)$. Sand fraction transport is determined by the Van Rijn (1993) transport equation. The transport of cohesive mud fractions is modeled by the Partheniades-Krone formulations (Krone 1962, 1993; Ariathurai 1974):

$E=M p_{e}\left(\tau_{c w}, \tau_{c r, e}\right)$

$D=w_{s} c_{b} p_{d}\left(\tau_{c w}, \tau_{c r, d}\right)$

where $E$ is the erosion flux $\left(\mathrm{kgm}^{-2} \mathrm{~s}^{-1}\right) ; M$ is the erosion rate constant $\left(\mathrm{kgm}^{-2} \mathrm{~s}^{-1}\right) ; D$ is the deposition flux $\left(\mathrm{kgm}^{-2} \mathrm{~s}^{-1}\right) ; w_{\mathrm{s}}$ is the sediment fall velocity $(\mathrm{m} / \mathrm{s}) ; c_{\mathrm{b}}$ is the near-bottom concentration $\left(\mathrm{kg} / \mathrm{m}^{3}\right) ; \tau_{\mathrm{cw}}$ is the maximum shear stress due to waves and current $(\mathrm{Pa})$; $\tau_{\text {cr,e }}$ is the critical shear stress for erosion $(\mathrm{Pa})$; and $\tau_{\mathrm{cr}, \mathrm{d}}$ is the critical shear stress for deposition (Pa)and

$$
\begin{aligned}
p_{e}\left(\tau_{c w}, \tau_{c r, e}\right) & =\left(\frac{\tau_{c w}}{\tau_{c r, e}}-1\right) & & \text { for } \tau_{c w} \tau_{c r, e} \\
& =0 & & \text { for } \tau_{c w} \leq \tau_{c r, e} \\
p_{d}\left(\tau_{c w}, \tau_{c r, d}\right) & =\left(1-\frac{\tau_{c w}}{\tau_{c r, d}}\right) & & \text { for } \tau_{c w} \tau_{c r, d} \\
& =0 & & \text { for } \tau_{c w} \geq \tau_{c r, d}
\end{aligned}
$$

The erosion rate constant $(M)$ is set at $5.0 \times 10^{-5} \mathrm{kgm}^{-2} \mathrm{~s}^{-1}$. This value is comparable to earlier modeling studies of
McDonald and Cheng (1997) who used $1-5 \times 10^{-5} \mathrm{kgm}^{-2} \mathrm{~s}^{-1}$ and Ganju and Schoellhamer (2010) with values of $1.8 \times 10^{-5}$ and $2.0 \times 10^{-5} \mathrm{kgm}^{-2} \mathrm{~s}^{-1}$ and Ganju et al. (2009) with a constant $2.0 \times 10^{-5} \mathrm{kgm}^{-2} \mathrm{~s}^{-1}$. Teeter (1987) measured values ranging from 1.3 to $4.7 \mathrm{kgm}^{-2} \mathrm{~s}^{-1}$ for the Alcatraz disposal site in the Central Bay. The critical shear stress for deposition $\left(\tau_{\text {cr-d }}\right)$ is set at 1,000 Pa, following suggestions by Winterwerp and Van Kesteren (2004), pp 144-148. This implies that deposition becomes a function only of concentration and fall velocity. Mud fraction characteristics are given in Table 2. The sand fractions are initially only present in the channel area, that is, in the area deeper than $5 \mathrm{~m}$ below MSL (see Fig. 2a), whereas the mud fractions are initially assigned to areas shallower than $5 \mathrm{~m}$. This is in accordance with observed allocations by Locke (1971) (see also Fig. 2b).

\section{Results}

\subsection{General}

Figure 5 shows the sediment load in terms of transported dry sediment volume per second averaged over San Pablo Bay for 2 and 15 days after the start of the run. Figure 6 plots the daily envelopes of sediment load averaged over the bay, and Fig. 7 shows the change in percentage of the different fractions in the first bed layer (averaged over the bay). These results show initially high rates of sediment redistribution. Rates of change of the mud fractions are $100-200 \%$ higher than those of sand. As expected, the finer fractions show the most pronounced signals. Sand fractions show immediately decaying loads, whereas mud fractions reach a peak after some time. This is attributed to the different timescales of transport of sand and mud. Mud requires a number of tidal cycles in which it deposits and resuspends until reaching a "suitable," low shear stress area, whereas sand is reallocated relatively quickly in a smaller and deep domain (the channel area) in which relatively constant shear stresses prevail. The finer mud fraction loads reach their peak earlier than the heavier mud fractions. This is attributed to the fact that the finer fractions are more easily transported and washed out of the model domain or reallocated to areas of lower shear stresses. The $\mathrm{m}_{1}$ fraction shows the highest rates only after some days. This is probably because this fraction becomes more exposed

Table 2 Selected characteristic parameters of mud fractions $\mathrm{m}_{1}, \mathrm{~m}_{2}$, and $\mathrm{m}_{3}$

Critical shear stress $\left(\tau_{\text {cr-e }}, \mathrm{Pa}\right)$

Fall velocity $\left(w_{\mathrm{s}}, \mathrm{mm} / \mathrm{s}\right)$

\begin{tabular}{lll}
\hline $\mathrm{m}_{1}$ & 0.8 & 0.8 \\
$\mathrm{~m}_{2}$ & 0.5 & 0.5 \\
$\mathrm{~m}_{3}$ & 0.3 & 0.3 \\
\hline
\end{tabular}


Fig. 5 Sediment load averaged over San Pablo Bay for three sand fractions (thick lines) and three mud fractions (thin lines). Results shown cover a period of 15 days after the start of the model run of 2-day duration

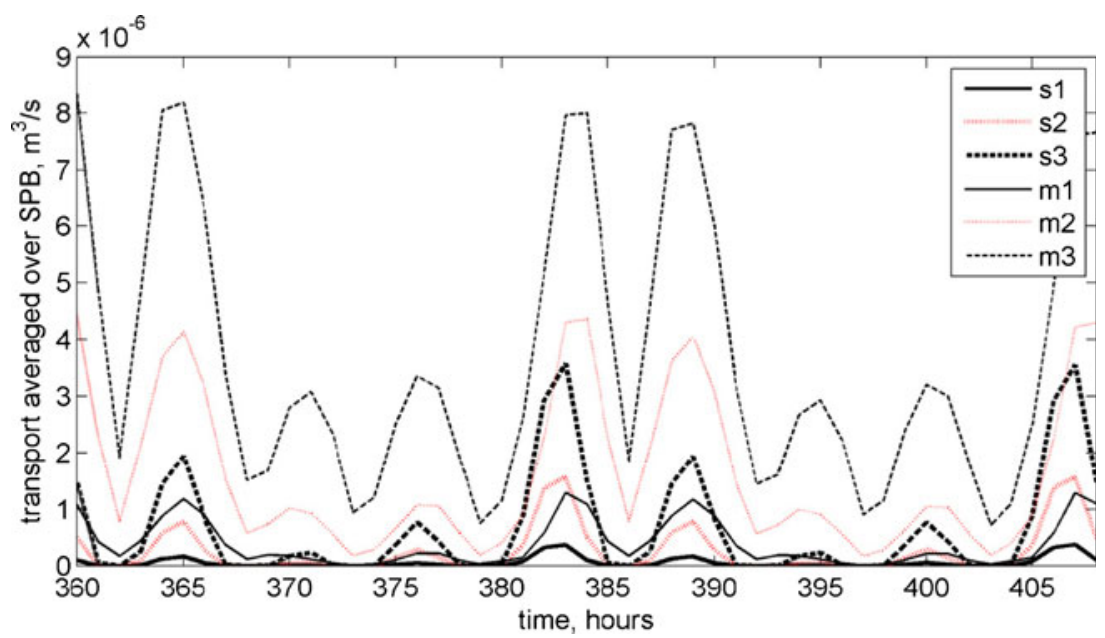

only after a time period in which the finer $\mathrm{m}_{2}$ and $\mathrm{m}_{3}$ fractions are washed away.

After approximately 10 days, sediment loads and changes in the bed composition decrease considerably. Still, significant tide-induced fluctuations can be observed (Fig. 5). Mud is redistributed so that the coarsest fractions are present along the channel sides, and even some mud deposits are found after 20 days in the eastern part of the channel (Fig. 8). The finest mud fraction $\mathrm{m}_{3}$ accumulates along a band crossing the middle of the northern shallow area. This band barely moves after 20 days. Sand remains in the channel and the sand fractions are somewhat redistributed. The boundary between the shoal and the channel becomes more gradual in terms of sediment composition. Figure 8 shows sediment distribution after 20 days. The measurements (Locke 1971; see Fig. 2b) show that the coarsest silty or sandy sediment finds it way into the channel and that the finest sediment $\left(D_{50}<4 \mu \mathrm{m}\right)$ is located on the shoals. Material with a grain size between 2 and $64 \mu \mathrm{m}$ is found in patches in the channel area and close to the land boundaries of the shoals.

It is difficult to interpret the measured $D_{50}$ values in terms of the mud characteristics applied in the present model. However, mud on the shoals may have settled as flocs so that the dispersed particle size measured cannot be related directly to the fall velocity. Furthermore, we are not aware of a generally applicable relationship between $D_{50}$ $(<62 \mu \mathrm{m})$ and the critical shear stress or the erosion rate constant.

Still, there is a resemblance between the measurements and model results. The coarsest fractions are found in the channel area and the finest fractions on the shoals. Similar to the measured medium grain size $\left(2 \mu \mathrm{m}<D_{50}<64 \mu \mathrm{m}\right)$, the $m_{1}$ fraction occurs in patches in the channel area. The measured medium grain size is found close to the land boundary of the shoals and surrounds finer grain sizes. This is attributed to wind waves that have a relatively high impact on the prevailing shear stresses on the shallower parts of the shoals close to the land boundary. Since wind waves are not modeled in this study, this latter effect is not observed in the model results.

\subsection{Sensitivity analysis}

Model results can be expected to be sensitive to variation in model parameters such as relative to the boundary
Fig. 6 Envelopes of sediment loads averaged over San Pablo Bay for three sand fractions (a) and three mud fractions (b). Envelopes represent daily maximum and minimum loads (see Fig. 5 for inter-diurnal values). The lowest envelopes almost coincide with the origin
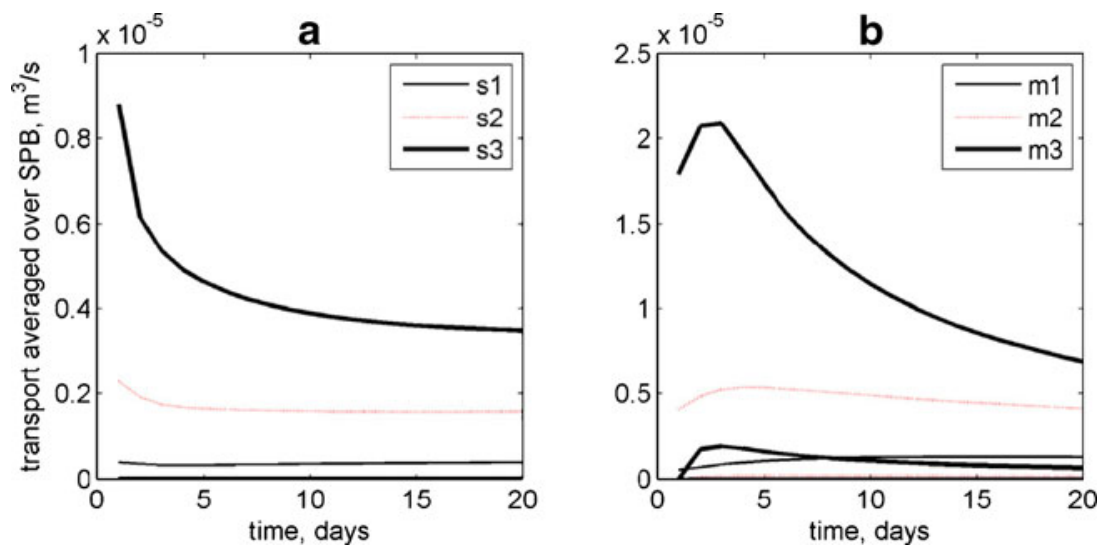
Fig. 7 Envelopes of change in bed composition in the upper bed layer in terms of volume fraction change per hour (in \%) averaged over San Pablo Bay for three sand fractions (a) and three mud fractions (b). Envelopes represent daily maximum and minimum values. The lowest envelopes coincide for the three sand fractions (a) or nearly coincide with the origin for the three mud fractions (b)

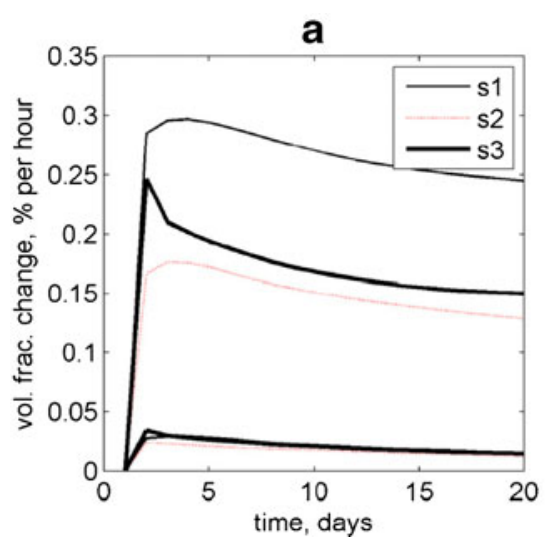

conditions, boundary roughness, and coefficients related to sediment transport and bed composition. Sensitivity analysis was carried out on variations in the morphological factor and the active layer depth, as well as on the effect of waves. The standard case applied a morphological factor of 100, an active layer of $25 \mathrm{~cm}$, and did not include waves. Waves were modeled by imposing a constant and uniform wind field of $10 \mathrm{~m} / \mathrm{s}$ from the west. This wind field generated wave heights of $0.6 \mathrm{~m}$ maximum in the eastern part of the channel area.

Figure $9 \mathrm{a}, \mathrm{b}$ shows the daily maximum values of $\mathrm{s}_{2}$ and $\mathrm{m}_{2}$ sediment loads averaged over San Pablo Bay (these fractions are representative of the behavior of the other fractions). Doubling or halving the morphological factor leads to, respectively, about a $25 \%$ decrease or increase in the $\mathrm{m}_{2}$ fraction load after 30 days. The application of a higher morphological factor leads to faster adaptation of the bed composition. This implies that mud fractions are reallocated faster so that the bed is able to withstand the prevailing bed shear stresses after a relatively short period of time. The reallocation process takes longer for lower morphological factors. However, the bed composition from a run with a morphological factor of 50 after 30 days did not differ significantly from a run with a morphological factor of 200 after 7.5 days (not shown). Similarly, Fig. 9b shows that mud loads are comparable for runs with a morphological factor of 100 after 15 days and a factor of 50 after 30 days. The run with a factor of 200 after 7.5 days shows a slight deviation, but this is due to the initially high transport rates.

The effect of variations in the morphological factor is much less pronounced for sand transport. This is attributed to the geometry as sand is allocated to the deep channel area where the shear stresses are relatively invariant, so that the rate of sand reallocation has only a minor effect on transport loads. In contrast, mud fractions are dispersed toward areas with significantly lower shear stresses.

A closer inspection of the model results (not shown) indicated that the morphological factor of 100 leads to an underlayer thickness reduction rate of $4 \mathrm{~cm}$ maximum per time step. This rate occurs immediately after the start of the run, at the northwestern (submerged) bank of the channel. It is about $20 \%$ of the active layer thickness, so a factor of 100 (or even slightly higher) is acceptable. For full morphodynamic runs (see following paragraphs), the bed level change should be smaller than $5 \%$ of the local water depth (about $5 \mathrm{~m}$ ), so feedback mechanisms between the flow and the bed level development can be neglected.

Doubling the active layer thickness leads to a longer adaptation timescale which is comparable to halving the morphological factor. A probable explanation is as follows. Assume two cases in which case A has an active layer thickness of $0.25 \mathrm{~m}$ and case B of $0.5 \mathrm{~m}$. In both cases, the sediment consists of $20 \%$ fine fraction. After one time step, $0.05 \mathrm{~cm}$ of fines erodes from the active layer. This means that all fines are washed out of the active layer in case $\mathrm{A}$ and $50 \%$ in case $\mathrm{B}$. The eroded volume is replaced by an equal volume from the underlayer consisting for $20 \%$ of fines. After one time step, the active layer of case A consists of $4 \%$ fines (20\% of $20 \%$ ) and case B 10\% (the volume of fines that did not erode) $+2 \%(20 \%$ of $10 \%)=12 \%$ fines. Since the eroding volumes are proportional to the fraction in the active layer, subsequent time steps lead to larger volumes of fines being eroded from case B, which is confirmed in Fig. 9b. Although doubling the active layer thickness leads to longer adaptation timescales, there is no deviation in the trend.

Including waves leads to initially slightly larger sand loads and the prevalence of larger mud loads. Waves ensure that mud on the shoals is kept in suspension. The transport trend with waves does not deviate much from the trend without waves. This suggests the mud suspended by wave action is not washed out of the modeling domain, but deposits and erodes in the same general area (mainly the northern shoal). Waves only influence sand transport in the beginning by reallocating the sand fractions on the shoals, but ultimately, the run with waves present leads to similar sand loads as for the other cases. 
Fig. 8 Distribution of sediment fractions over San Pablo Bay after 20 days. White area denotes $0 \%$ and black $100 \%$ presence in the first bed layer (the upper $20 \mathrm{~cm}$ ). Contours reflect 5-m depths in 1856.

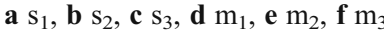
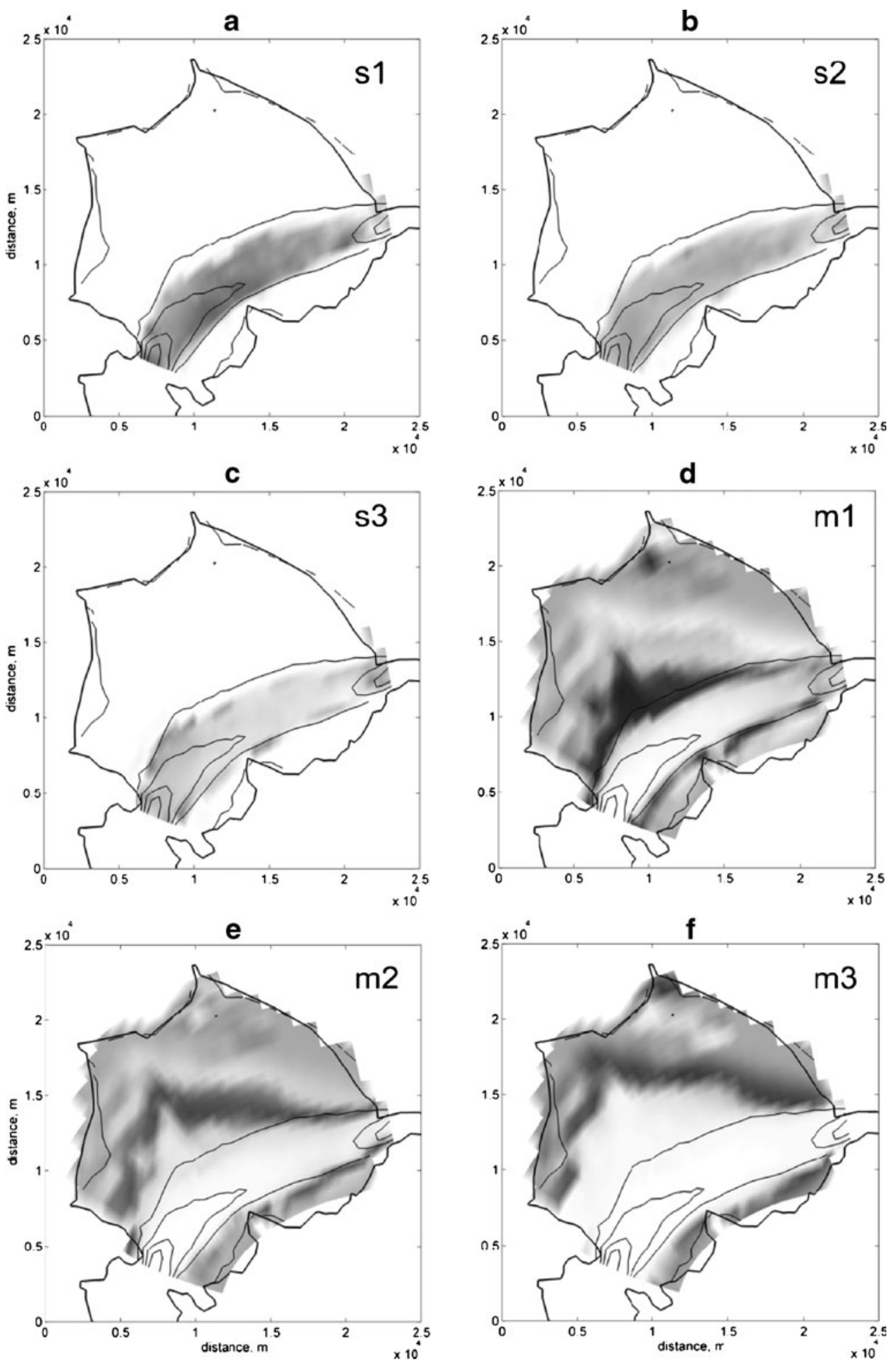

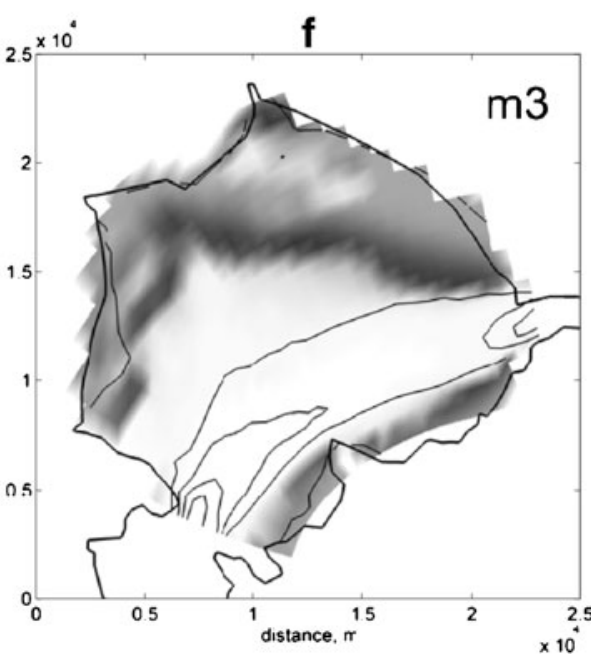

\subsection{Morphodynamic runs}

The output of the BCG run can be used as the input for morphodynamic runs that permit bed-level changes. Figures 10,11 , and 12 show comparisons of the morphodynamic runs starting from a uniform bed (applying the same initial condition as in the bed generation run) and from a bed in which the composition of both the active layer and the underlayer are defined by the composition of the upper layer of the BCG run result.

The run with BCG leads to significantly smaller sand and $\mathrm{m}_{3}$ fraction loads. Although the initial loads are somewhat larger, the run without BCG leads at times to somewhat smaller loads of both the $m_{1}$ and the $m_{2}$ fractions. For almost 
Fig. 9 Daily maximum sediment loads averaged over San Pablo Bay under different model parameter settings, i.e., standard case with morphological factors of 50 and 200 , an active layer of $0.5 \mathrm{~m}$, or inclusion of waves for sand fraction 2 (note that lines of $\mathrm{AL}=0.5$ and morphological factor $=50$ almost coincide) (a) and mud fraction 2 (b)

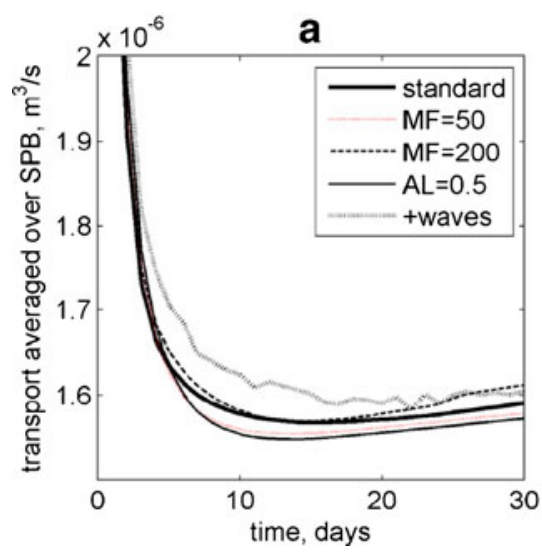

b

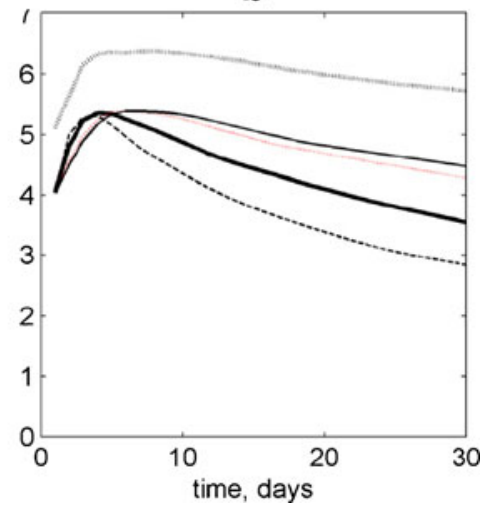

all fractions, the initial peak loads of the BCG run are significantly smaller (Fig. 10).

Changes of the bed volume in the run with BCG are 50\% smaller than volumetric changes in the run without BCG (Fig. 11), and they decay less with time at lower rates. The erosion and sedimentation patterns after 30 days are qualitatively similar (Fig. 12), although the loads in the run with BCG are much lower. A significant difference occurs on the northwestern channel bank, which is also the area where the mud and sand fractions were separated (5-m depth contour) and where the $\mathrm{m}_{1}$ fraction replaced the sand fraction during the run with BCG (see also Fig. 8c, d). A likely cause in the run without $\mathrm{BCG}$ is that fine mud fractions from the northern channel bank are reallocated toward the northern shoal and the northeastern channel bank. Compare for example Figs. 12a and $8 \mathrm{e}, \mathrm{f}$. This process was already taken into account in the run with $\mathrm{BCG}$. The initial sediment reallocation in the run without BCG leads to loads and erosion and sedimentation volumes that are similar to the more "autonomous" development reflected in the run with BCG.

\section{Discussion}

The model results show that a BCG run leads to a lesser sediment load in the model domain because sediment is redistributed according to locally prevailing shear stresses. A run allowing for bed-level development starting from bed composition from a BCG run leads initially to significantly smaller sediment loads and lesser morphodynamic development in terms of basin-averaged sediment loads and bedlevel changes.

One can explain these results in terms of a "morphodynamic spin-up" of the model. Hydrodynamic spin-up usually refers to the time period required for the flows within the model domain to adapt to the specified boundary conditions. Only after this period does hydrodynamic validation against measurements take place. Also, bedlevel updates are usually carried out after hydrodynamic spin-up so that bed-level updates are not influenced by initially irregular variations in flows. Similar to a hydrodynamic spin-up, the initial bathymetric development is influenced by a morphodynamic spin-up which adjusts the bathymetry to the model parameter settings related to the sediment loads and bed composition rather than describe the actual behavior of the modeled system. The BCG run may shorten and decrease the effect of the morphodynamic spin-up. It is stressed that the proposed methodology does not lead to a disappearance of the sediment load peaks during the initial period of the morphodynamic run, but it reduces them and the period in which the bathymetry needs to adapt.
Fig. 10 Daily maximum values of sediment loads averaged over San Pablo Bay for three sand fractions (a) and three mud fractions (b). Both runs allowed for bed level updates. Thin lines refer to runs with a uniform initial bed composition. Thick lines refer to runs based on an initial bed generated from a BCG run. Thin lines refer to run starting from uniform sediment distribution
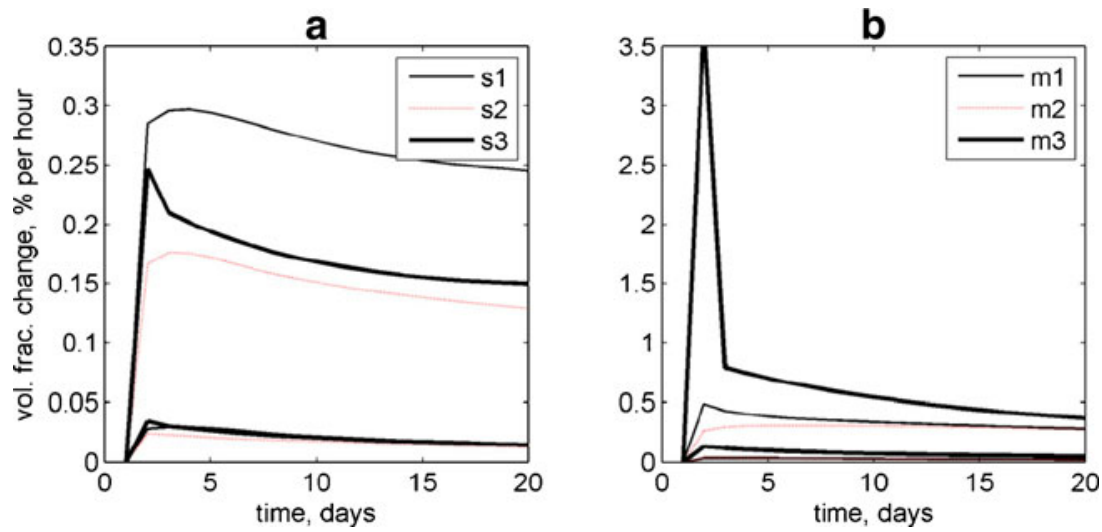


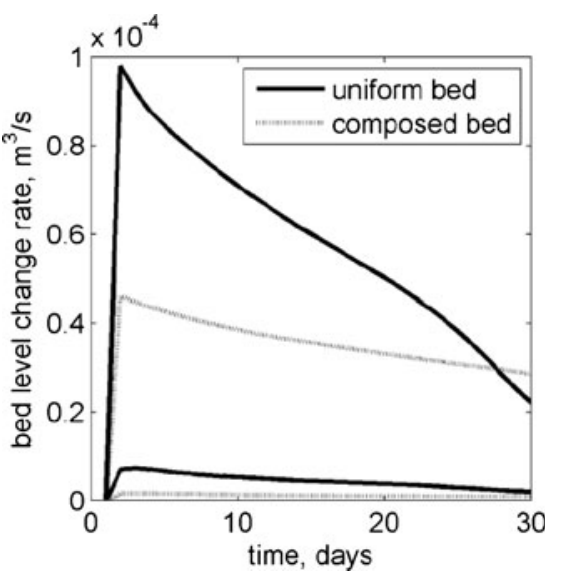

Fig. 11 Envelopes of bed volume change per second averaged over San Pablo Bay including morphodynamic development

The following general remarks are worthy of note with respect to the proposed methodology.

- There is no strict criterion regarding how long a BCG run should take. In the present study, the BCG runs were longer than the duration of the initial load peaks occurring in the first couple of days.

- The BCG run should not take too long since there is a risk that bed levels become almost fixed due to sediment redistribution such that (dynamic) conditions found in reality are not reproduced.

- The duration of the BCG run should depend on the duration of forcing conditions in reality. The present work simulates a BCG run of 30 days with a morphological factor of 100 . This means that from a morphological perspective, conditions are modeled for 3,000 days. In the case of San Pablo Bay, this is an order of magnitude larger than the dry period of about 300 days. Effects of high river discharges are not taken into account.

- One may argue that the BCG run should indeed be longer than the characteristic timescale of system dynamics (such as the yearly wet-dry season cycle). By considering multiple fractions and their assumed characteristics, the BCG run introduces more degrees of freedom into the system which requires longer adaptation times.

- The duration of the BCG run, the morphological factor, the active layer thickness, and sediment characteristics must be established on a case-by-case basis.

- The BCG run defines a best guess for the initial bed composition of the active layer of a full morphodynamic run. Still, the composition of the underlayers is not defined by this methodology. Bed composition is probably a function of historical developments including consolidation processes rather than a function of prevailing present-day bed shear stresses. A simple but rough approach would be to assign the same composition defining values as for the active layer, but with higher critical shear stresses.

In summary, an important, but difficult to determine criterion for successful implementation of a BCG run is that morphodynamic development due to the assumed initial bed composition be reduced to a level which does not subsume the autonomous development of the system to be modeled.

\section{Conclusions}

Process-based morphodynamic models require an adequate description of the initial bed composition to generate reliable predictions of morphodynamic development. Bed composition in which the sediment fractions are uniformly distributed over the model domain initially leads to peaks in sediment loads and rates of bed level development. Only after some days do the loads and bed level changes decrease and show a more gradual development. The peaks are associated with a morphodynamic spin-up in which the model adapts to the bed level and the bed composition according to the model parameter settings rather than describe a realistic behavior of the system.
Fig. 12 Erosion (-) and sedimentation $(+)$ patterns in San Pablo Bay after 30 days (with a morphological factor of 100) starting from uniformly distributed sediments (a) and from a model-generated bed distribution (b)
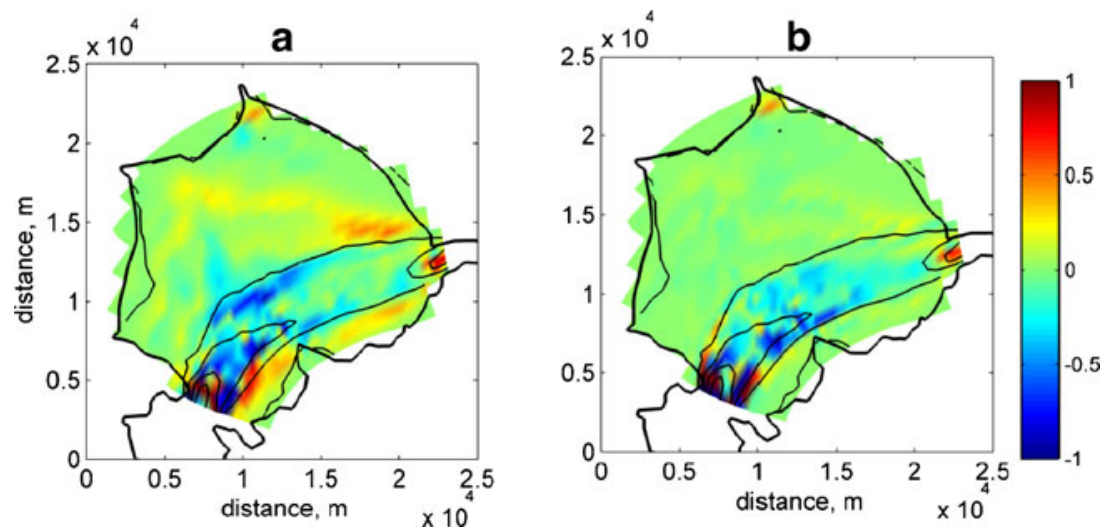
The present research proposes a methodology to generate bed sediment composition that can act as the initial condition for a full morphodynamic run. The BCG run does not include actual bed-level changes but allows for the redistribution of multiple sediment fractions over the model domain.

Model results applied to San Pablo Bay show that a BCG run reallocates sand and mud fractions over the modeling domain. Results show that initially, a major sediment redistribution takes place. After this period, a more gradual development is observed, reflecting lesser sediment dynamics in terms of sediment loads and changes in the bed composition. Decreasing the value of the morphological factor, increasing the active layer thickness or including wind waves shortens the adaptation timescale, but does not change the general trend. Morphodynamic runs allowing for bed level changes and with bed composition based on a BCG run lead to lower initial peaks in sediment loads and a more gradual bathymetric development compared to runs starting from a uniform bed composition. The decrease in initial sediment load peaks suggests that the methodology leads to model performance that is less disturbed by ill-defined initial conditions in bed composition. However, a strict criterion for the required length of a BCG run could not be determined.

Future research will focus on a decadal morphodynamic hindcast and comparison with sequential bathymetries in San Pablo Bay so that the proposed methodology can be further tested and optimized.

Acknowledgment This research has been part of the USGS CASCaDE climate change project. The authors wish to acknowledge USGS Priority Ecosystem Studies, CALFED, as well as UNESCOIHE research funding for making this research possible.

Open Access This article is distributed under the terms of the Creative Commons Attribution Noncommercial License which permits any noncommercial use, distribution, and reproduction in any medium, provided the original author(s) and source are credited.

\section{References}

Ariathurai CR (1974) A finite element model for sediment transport in estuaries. PhD thesis, University of California, Davis

Blom A (2008) Different approaches to handling vertical and streamwise sorting in modeling river morphodynamics. Water Resour Res 44:W03415. doi:10.1029/2006WR005474

Booij N, Ris RC, Holthuijsen LH (1999) A third-generation wave model for coastal regions. Part I. Model description and validation. J Geophys Res 104 C4:7649-7666

Cappiella K, Malzone C, Smith R, Jaffe BE (1999) Sedimentation and bathymetric change in Suisun Bay 1876-1990. USGS Open File Report 9-563
De Vriend HJ, Capobianco M, Chesher T, De Swart HE, Latteux B, Stive MJF (1993) Approaches to long term modeling of coastal morphology: a review. Coastal Eng 21(1-3):225-269

Ganju NK, Schoellhamer DH (2007) Calibration of an estuarine sediment transport model to sediment fluxes as an intermediate step for simulation of geomorphic evolution. Continental Shelf Research. doi:10.1016/j.csr.2007.09.005

Ganju NK, Schoellhamer DH (2010) Decadal-timescale estuarine geomorphic change under future scenarios of climate and sediment supply. Estuaries Coasts 33:15-29. doi:10.1007/ s12237-009-9244-y

Ganju NK, Schoellhamer DH, Murrell MC, Gartner JW, Wright SA (2007) Constancy of the relation between floc size and density in San Francisco Bay. In: Maa JP-Y, Sanford LP, Schoellhamer DH (eds) Estuarine and coastal fine sediments dynamics. Elsevier Science B.V, Amsterdam, pp 75-91

Ganju NK, Knowles N, Schoellhamer DH (2008) Temporal downscaling of decadal sediment load estimates to a daily interval for use in hindcast simulations. J Hydrol 349:512523

Ganju NK, Schoellhamer DH, Jaffe BE (2009) Hindcasting of decadal-timescale estuarine bathymetric change with a tidaltimescale model. J Geophys Res 114:F04019. doi:10.1029/ 2008JF001191

Hirano M (1971) River bed degradation with armouring. Trans Jpn Soc Civ Eng 3:194-195

Hoitink AJF, Hoekstra P, Van Maren DS (2003) Flow asymmetry associated with astronomical tides: implications for the residual transport of sediment. J Geophys Res 108(C10):3315

Jaffe BE, Smith RE, Foxgrover AC (2007) Anthropogenic influence on sedimentation and intertidal mudflat change in San Pablo Bay, California: 1856 to 1893. Estuar Coast Shelf Sci 73(1-2):175187. doi:10.1016/j.ecss.2007.02.17

Jones C (2008) Aquatic transfer facility sediment transport analysis. In: Cacchione DA, Mull PA (eds) Technical studies for the aquatic transfer facility: Hamilton Wetlands Restoration Project. US Army Corps of Engineers, San Francisco District, Hamilton Wetland Restoration Project Aquatic Transfer Facility Draft Supplemental EIS/EIR, Appendix A, Chapter 4, pp 305-340. http://www.hamiltonwetlands.org/hw_media/ docs/HamiltonATFSEISAppendices.pdf

Kimmerer WJ (2004) Open Water processes of the San Francisco Estuary: from physical forcing to biological responses. San Francisco Estuary and Watershed Science (online serial), vol. 2, Issue 1, art 1. http://repositories.cdlib.org/jmie/sfews/vol2/ iss $1 /$ art 1

Krone RB (1962) Flume studies of the transport of sediment in estuarial shoaling processes. Final Report Hydraulic Engineering Laboratory and Sanitary Engineering Research Laboratory, University of California, Berkeley

Krone RB (1993) Sedimentation revisited. In: Mehta AJ (ed) Nearshore and estuarine cohesive sediment transport. AGU, Coastal and Estuarine Studies, pp 108-125

Lanzoni S, Seminara G (2002) Long-term evolution and morphodynamic equilibrium of tidal channels. J Geophys Res 107 (C1):3001. doi:10.1029/2000JC000468

Lesser GR (2009) An approach to medium-term coastal morphological modelling. PhD thesis, UNESCO-IHE \& Delft Technical University Delft the Netherlands, CRC Press/Balkema. ISBN 978-0-415-55668-2

Lesser GR, Roelvink JA, Van Kester JATM, Stelling GS (2004) Development and validation of a three-dimensional morphological model. Coastal Eng 51:883-915

Locke JL (1971) Sedimentation and foraminiferal aspects of the recent sediments of San Pablo Bay. MSc thesis, Faculty of the Department of Geology, San Jose State College 
McDonald ET, Cheng RT (1997) A numerical model of sediment transport applied to San Francisco Bay, California. J Mar Environ Eng 4:1-41

Roelvink JA (2006) Coastal morphodynamic evolution techniques. Coastal Eng 53:177-187

Seminara G, Blondeaux P (2001) Perspectives in morphodynamics. In: Seminara G, Blondeaux P (eds) River, coastal and estuarine morphodynamics. Springer, Berlin

Teeter AM (1987) Alcatraz disposal site investigation, San Francisco Bay; Alcatraz disposal site erodibility. Report 3. Misc Paper HL86-1 US Army Eng. Waterway Exp. Station, Vicksburg, MS

Todeschini I, Toffolon M, Tubino M (2008) Long-term morphological evolution of funnel-shape tide-dominated estuaries. J Geophys Res 113:C05005.1-C05005.14

Van der Wegen M, Roelvink JA (2008) Long-term morphodynamic evolution of a tidal embayment using a two-dimensional, process-based model. J Geophys Res 113:C03016. doi:10.1029/ 2006JC003983
Van der Wegen M, Wang ZB, Savenije HHG, Roelvink JA (2008) Long-term morphodynamic evolution and energy dissipation in a coastal plain, tidal embayment. J Geophys Res 113:F03001. doi:10.1029/2007JF000898

Van Ledden M, Wang ZB, Winterwerp JC De Vriend HJ (2006) Modelling sand-mud morphodynamics in the Friesche Zeegat. Ocean Dyn 56(3-4):248-265

Van Rijn LC (1993) Principles of sediment transport in rivers, estuaries and coastal seas. AQUA Publications, the Netherlands

Winterwerp JC, Van Kesteren WGM (2004) Introduction to the physics of cohesive sediment in the marine environment. Developments in sedimentology 56. Elsevier, Amsterdam

Yongjun Lu, Ji R, Zuo L (2009) Morphodynamic responses to the deep water harbor development in the Caofeidian Sea area, China's Bohai Bay. Coastal Eng 56:831-843

Zanuttigh B (2007) Numerical modelling of the morphological response induced by low-crested structures in Lido di Dante, Italy. Coastal Eng 54-1:31-47 